\title{
Capacity utilization in resilient wavelength-routed optical networks using link restoration
}

\section{Limal, Emmanuel; Danielsen, Søren Lykke; Stubkjær, Kristian}

\section{Published in:}

Technical Digest Optical Fiber Communication Conference and Exhibit

Link to article, DOI:

10.1109/OFC.1998.657415

Publication date:

1998

Document Version

Publisher's PDF, also known as Version of record

Link back to DTU Orbit

Citation (APA):

Limal, E., Danielsen, S. L., \& Stubkjær, K. (1998). Capacity utilization in resilient wavelength-routed optical networks using link restoration. In Technical Digest Optical Fiber Communication Conference and Exhibit (pp. 297-298). IEEE. https://doi.org/10.1109/OFC.1998.657415

\section{General rights}

Copyright and moral rights for the publications made accessible in the public portal are retained by the authors and/or other copyright owners and it is a condition of accessing publications that users recognise and abide by the legal requirements associated with these rights.

- Users may download and print one copy of any publication from the public portal for the purpose of private study or research.

- You may not further distribute the material or use it for any profit-making activity or commercial gain

- You may freely distribute the URL identifying the publication in the public portal 


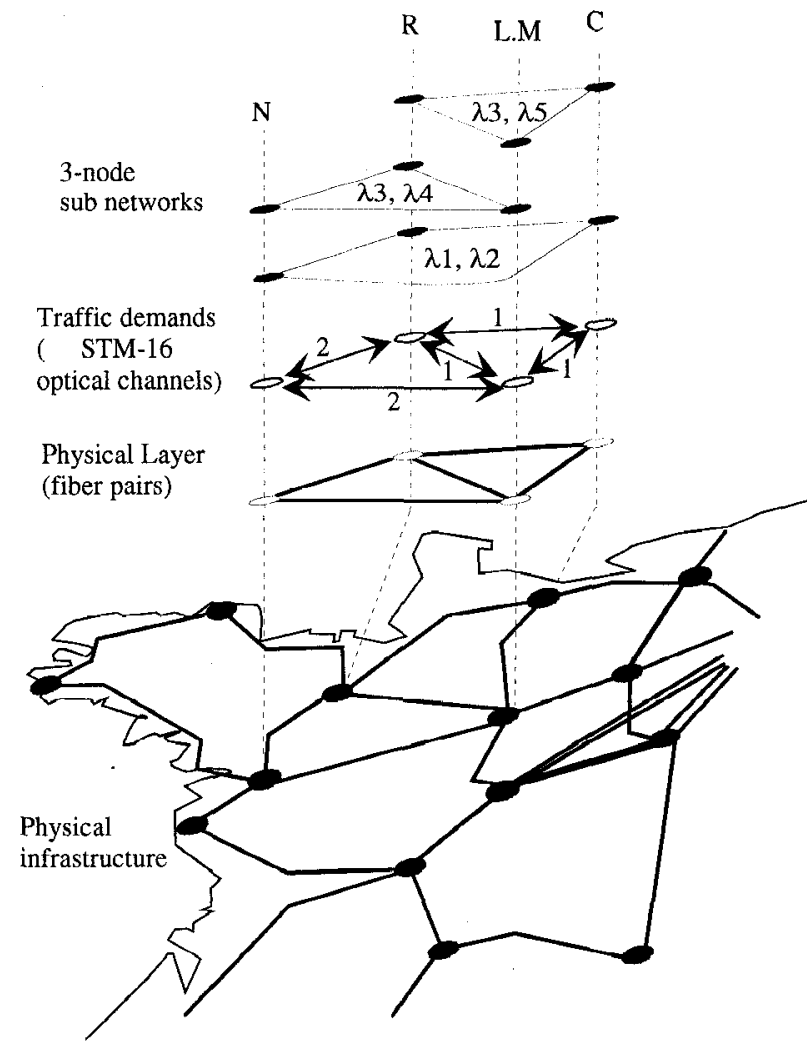

ThJ2 Fig. 2. Application of network design in the French optical core network.

fails. As seen in Fig. 1, $2 \times 2$ switches select the spare path $(\lambda 2$ is either through or dropped). A test bed has been built, which demonstrates both feasability and compatibility with existing systems. The use of small-size switches and the simple logical topology ensures typical APS restoration times.

Our novel approach considers the three-node logical mesh as a building block for any meshed network. Any two-connected physical network is indeed composed of a set of three-node subnetworks. Heuristic algorithms are proposed to find the minimum cost decomposition. In particular, we show that a full n-node logical mesh can be subdivided into $\lceil\mathrm{n} / 3 *\lceil(\mathrm{n}-1) / 2\rceil\rceil$ subnetworks. As seen in Fig. 2, we take benefit from WDM because several three-node subnetworks may share a common fiber pair, provided they are assigned different wavelength combs. Thus

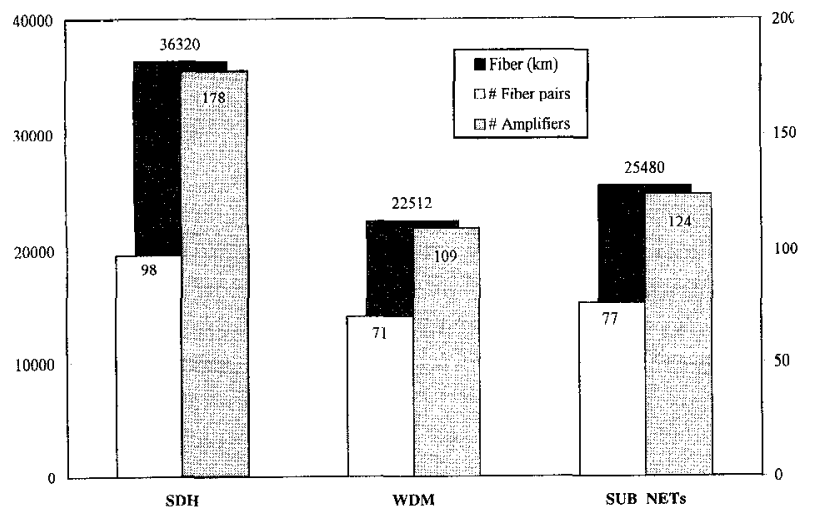

ThJ2 Fig. 3. Required amount of equipment (optical fiber and optical amplifiers) for the three network upgrade scenarios. the great advantage of this approach is to benefit from WDM for increasing the link capacities, while ensuring fast network configuration through self-healing technicue. Moreover, network architecture is upgradable by adding new subnetworks whenever traffic increases.

An evolution of the French national transport layer has been studied, in which new traffic demands are conveyed in a WDM network. Cost evaluations were made for a $40 \%$ increase in traffic, relatively to already invested SDH systems. Three scenarios were compared: (1) use of more STM-16 systems with DCS restoration, (2) WDM layer with wavelength routing and end-to-end optical path protection, ${ }^{3}$ (3) WDM layer with superimposed three-node subnetworks (SUB_NETs). Figure 3 gives the main results in terms of number of fibers and optical amplifiers. It shows that the use of WDM (scenarios 2,3) provides significant savings in transmission cost. In conclusion, our approach (optimized SUB_NETs and APS) designs an upgradable architecture with much better restoration times than the wavelength path protection scheme at a low expense ( $14 \%$ in optical amplifiers cost).

1. M. Médart et al., in Optical Fiber Communication Conference, Vol. 6 of 1997 OSA Technical Digest Series (Optical Society of America, Washington, D.C., 1997), p. 314.

2. R.E. Wagner et al., IEEE J. Lightwave Technol. 14, 1349-1355 (1996).

3. K. Sato et al., in Proceedings of IEEE GLOBECOM, Vol. 3, 1994, pp. 1513-1520.

11:00am

\section{Capacity utilization in resilient wavelength-routed optical networks using link restoration}

\section{Emmanuel Limal, Søren L. Danielsen, Kristian E. Stubkjæer, Center of Broadband Telecommunications, Technical University of Denmark, DK-2800, Denmark; E-mail: el@emi.dtu.dk}

The construction of resilient wavelength-routed optical networks has attracted much interest. ${ }^{1}$ Many network topologies, path and wavelength assignment strategies have been proposed, e.g., Refs. 2,3. The assessment of network strategies is very complex and comparison is difficult. Here, we take a novel analytical approach in estimating the maximum capacity utilization that is possible in wavelength-division multiplexing (WDM) networks that are resilient against single link failures. The results apply to general network topologies and can therefore be used to evaluate the performance of more specific wavelength and path assignment algorithms.

The analytical expressions for the maximum capacity utilization are derived by applying graph theory to a general network with or without wavelength conversion. The derivation is for complete recovery from single link failures, considering only link restoration (the signals are re-routed between the end nodes of the failed link as opposed to path restoration). The network contains $n$ nodes with an average node degree $d$ (the node degree gives the number of links connected to the node). Moreover, the derivation assumes that each link has the same number of fibers and that each fiber carries the same number of wavelength channels, $c$.

The capacity utilization is defined as the ratio between the number of working wavelength channels and the total number of wavelength channels. For only one fiber per link the maximum capacity utilization is 


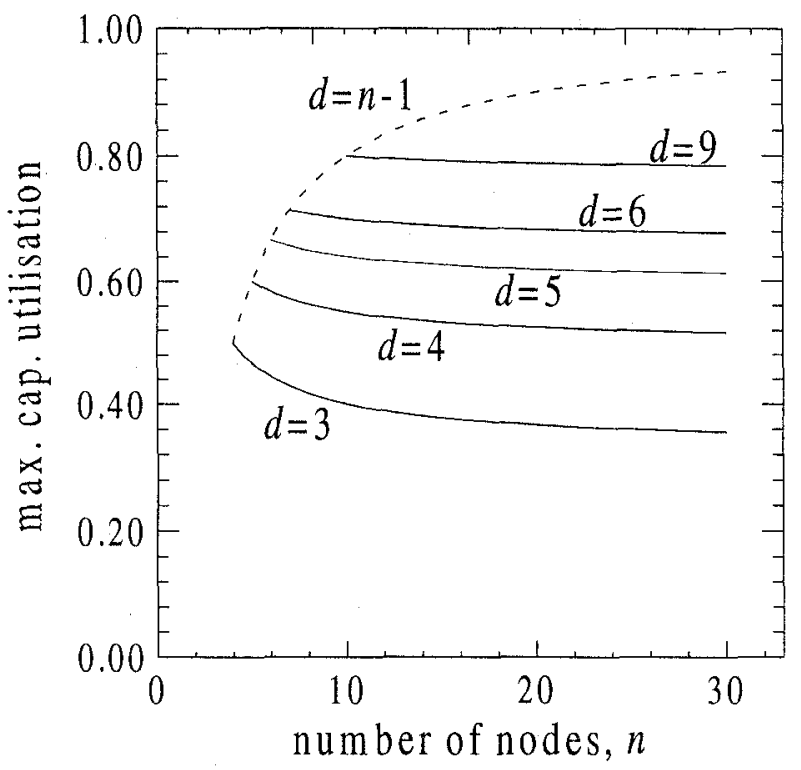

ThJ3 Fig. 1. Maximum capacity utilization of networks without wavelength conversion. The dashed line is for complete networks (each node connected to all others, $d=n-1$ ).

$1-2 / d+2 /(n d)$ in the case without wavelength conversion. In the case of wavelength conversion it is $1-1 / d$ and $1-1 / d-1 /(c d)+2 /(n c d)$ for an even and odd number of wavelength channels per fiber, respectively. Simple expressions can also be derived for more than one fiber per link. To keep the paper short we will, however, limit the following discussion to the case of one fiber per link.

Figure 1 gives the maximum capacity utilization versus the number of nodes without wavelength conversion. Only node degrees higher than 2 are considered, otherwise a strict link restoration strategy is not feasible with only one fiber per link and without wavelength conversion. The maximum utilization increases with the average node degree, $d$. It does, however, saturate as $d$ increases. For other practical reasons such as total

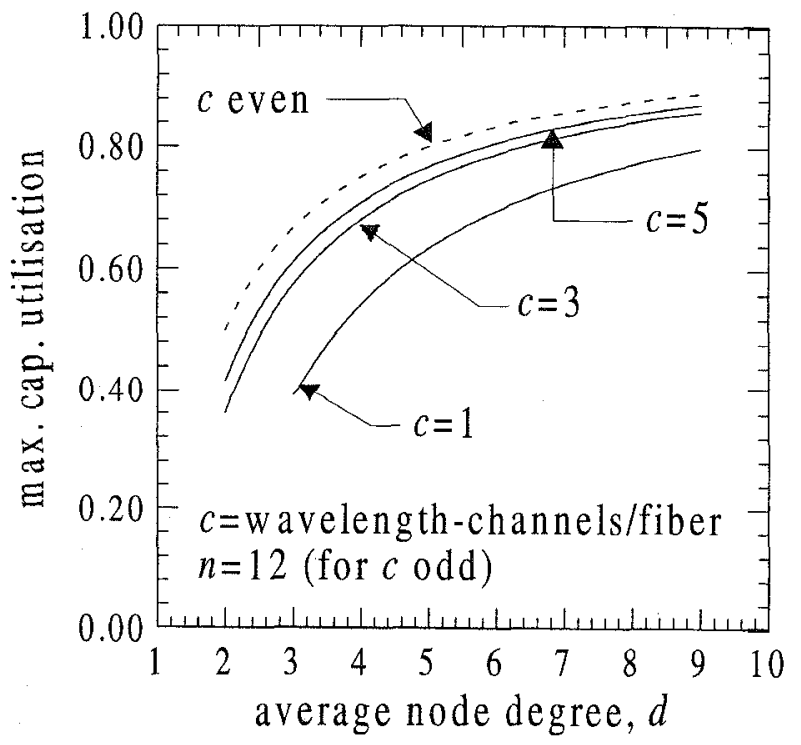

ThJ3 Fig. 2. Maximum capacity utilization of networks with wavelength conversion given for different number of wavelength channels, $c$, per fiber. The dashed line is for $c$ even. The solid lines are for $c$ odd and 12 nodes. Note that the case $c=1$ is equivalent to the case without wavelength conversion. cable length, node complexity and cross talk buildup, a very high $d$-value does not make sense. For $d=4$ the maximum network utilization is $50-60 \%$ depending on the number of nodes.

For the case of wavelength conversion in a network with 12 nodes, Fig. 2 gives the maximum utilization versus the average node degree, $d$, and for different number of wavelength channels. Note that the case of one wavelength channel corresponds to the case without conversion. As seen, the best utilization is achieved for even numbers of wavelengths. For $d=4$ the maximum utilization is $75 \%$, which is a significant increase compared to the case without conversion.

In the cases considered above, some rerouting paths would go through all the remaining nodes in the network. This may not be a feasible approach if the number of nodes is very big or the distances between nodes are large. Therefore, an approach with subnetworks could be taken. ${ }^{4,5}$ The maximum capacity utilization of the whole network would then depend on the subnetwork topologies.

To summarize, we have analyzed how the network parameters such as the number of nodes, average node degree and number of wavelengths influence the maximum capacity utilization. The results can be used as benchmarks for more specific network designs.

1. W.D. Grover, in Proceedings of GLOBECOM'87, Vol. 2, November 1987.

2. S. Subramaniam and R.A. Barry, in Proceedings of ICC'97, Vol. I, June 1997.

3. K. Bala and T.E. Stern, in Proceedings of IEEE INFOCOM'91, April 1991.

4. C.P. Larsen and E. Limal, to appear in proceedings of APCC'97, Sydney, Australia, December 1997.

5. E. Limal, B. Mikkelsen, K.E. Stubkjær, in Proceedings of ICC'97, June 1997.

ThJ4

11:15am

\section{A new algorithm for bi-directional link self-healing for arbitrary redundant networks}

Steven G. Finn, Muriel Médard, Richard A. Barry, Massachusetts institute of Technology, Lincoln Laboratory, 244 Wood Street, Lexington, Massachusetts 02173-9108; E-mail:finn@ll.mit.edu

Reliability is an important concern in high bandwidth optical networks because failures can disrupt many users and interrupt large amounts of communications. Automatic protection switching (APS), based on preplanned re-routing upon a failure, provides rapid recovery for edge and node failures. Two APS schemes have been widely used in SONET/SDH ring networks because of their rapid recovery times. The first, path protection, as used in UPSR, uses two independent routes simultaneously to provide failure protection. The second, loopback, as used in BLSR, uses backup routes only when the primary paths have failed (see Fig. 1). In general, loopback protection is more complicated to implement but is more bandwidth efficient than path protection because with loopback protection back-up capacity can be shared (see Fig. 2). A comparison of APS rerouting methods may be found in Ref. 4 .

Prior work ${ }^{1-3}$ proposed APS methods using path protection with multicast/broadcast trees that can be implemented on arbitrary edge/ node redundant networks. Here we present a new but related method for performing loopback APS for arbitrary edge/node redundant networks with bi-directional links. We call our new APS algorithm the Bi-direc- 